\title{
Status of active trachoma infection among school children who live in villages of open field defecation: a comparative cross- sectional study
}

\author{
Demoze Delelegn ${ }^{1}$, Alemu Tolcha² ${ }^{2}$ Hunachew Beyene ${ }^{3}$ and Berhan Tsegaye ${ }^{4^{*}}$
}

\begin{abstract}
Background: Although many efforts are made by different stakeholders, magnitude of active trachoma remains high among children in Ethiopia. Open field defecation was found to be the main source of active trachoma. However, comparative information on the effect of open field defecation and non-open field defecation on active trachoma is scarce in Ethiopia.

Methods: Comparative community based cross-sectional study was conducted from June 1-30, 2019 in Boricha and Dale districts to assess prevalence of active trachoma among primary school children. We have selected four primary schools purposively from two districts in Sidama. Study participants were selected by using simpe random sampling method. Data were collected through face to face interview, direct observation and ophthalmic examination. Logistic regression analysis was conducted to assess factors associated with active trachoma infection among primary school children. Adjusted Odds Ratios with 95\% confidence interval and $p$-value less than 0.05 were computed to determine the level of significance.

Result: From the total of 746 study participants, only 701 study participants gave full response for interview questions making a response rate of 94\%. The overall prevalence of active trachoma infection was $17.5 \%(95 \% \mathrm{Cl}$, 14.1-20.8) among primary school students. Specifically, prevalence of active trachoma infection was $67.5 \%$ among children who lived in open field defecation villages, but it was $88.5 \%$ among school children who live in Non-ODF Kebeles. Factors like: Living in open field defecation Kebeles ( $A O R=2.52,95 \% \mathrm{Cl}, 1.5-4.1)$, having ocular discharge $(A O R=5.715,95 \% C l, 3.4-9.4)$, having nasal discharge $(A O R=1.9,95 \% C l, 1.06-3.39)$, and fly on the face (AOR $=6.47$, $95 \% \mathrm{Cl}, 3.36-12.44)$ of children were positively associated with active trachoma infection. However, finger cleanness $(\mathrm{AOR}=0.43,95 \% \mathrm{Cl}, 0.21-0.9)$ was protective factor against active trachoma infection in this study.
\end{abstract}

\footnotetext{
* Correspondence: birieman67@gmail.com

${ }^{4}$ Department of Midwifery, College of Medicine and Health Science, Hawassa University, Hawassa, Ethiopia

Full list of author information is available at the end of the article
}

(c) The Author(s). 2021 Open Access This article is licensed under a Creative Commons Attribution 4.0 International License, which permits use, sharing, adaptation, distribution and reproduction in any medium or format, as long as you give appropriate credit to the original author(s) and the source, provide a link to the Creative Commons licence, and indicate if changes were made. The images or other third party material in this article are included in the article's Creative Commons licence, unless indicated otherwise in a credit line to the material. If material is not included in the article's Creative Commons licence and your intended use is not permitted by statutory regulation or exceeds the permitted use, you will need to obtain permission directly from the copyright holder. To view a copy of this licence, visit http://creativecommons.org/licenses/by/4.0/. The Creative Commons Public Domain Dedication waiver (http://creativecommons.org/publicdomain/zero/1.0/) applies to the data made available in this article, unless otherwise stated in a credit line to the data. 
Conclusion: Significant variation in prevalence of active trachoma infection among school children between open filed and non-open field defecation Kebeles was observed. Surprisingly, the prevalence in open field defecation was significantly lower than non-open field defecation. Hence, this indicates active trachoma infection highly depends on the hand hygiene than environmental sanitation. Educational campaign of hand hygiene should be enhanced in the community for school students.

Keywords: Open field defecation, Active trachoma, School children, Sidama

\section{Background}

Globally, active trachoma is predominant cause of preventable blindness. It is mainly caused by bacterium Chlamydia trachomatis. Trachoma infection is transmitted from infected to healthy person during contact of infected eye discharge though hands, clothing,fomites, and excreta [1]. Musca sorbens, eye-seeking fly, are the vector for active trachoma infection [2]. In Ethiopia, Bacterium Chlamydia trachomatis and Trachomatous trichiasis are concentrated in densely populated regions such as: Amhara, Oromia, and Sidama [3].

After the first infection, active trachoma is manifested sequentially in different clinical stages: First, trachoma manifests as a follicular conjunctivitis, with superficial keratitis and corneal vascularization. Second, it progresses to conjunctival scarring and eyelid distortion with repeated infection gradually. Third, cornea can be damaged. Finally, it can result into chronic inflammation and blindness $[4,5]$. Specifically, trachomatous inflammation-follicular (TF) presented as the occurrence of five or more small white follicles (each measure $\geq 0.5$ $\mathrm{mm}$ diameters) in the central zone of the upper tarsal conjunctiva. Over time, persistent abrasion of cornea by inward folding of eyelashes could lead to cornea opacification and blindness. Finally, repeated infection can lead to trachomatous trichiasis $[6,7]$.

Globally; an estimated 84 million people are suffering from active trachoma infection. According to World Health Organization (WHO) estimation, trachoma infection is an endemic disease in 56 Middle East and Africa countries. The problem can be doubled by lack of extensive resources necessary for prevention of trachoma such as: Access to clean water, sanitation facilities and health resources in developing countries [8]. Trachoma endemic communities are usually dry and dusty areas, mired in poverty, and have poor sanitation $[9,10]$. Trachoma is expected to be endemic throughout Ethiopia [11]. According to 2005-2006 national survey report, over 9 million children were affected by active trachoma [12]. Specifically, prevalence of active trachoma is expected to be high in the study area [13].

Children are the most vulnerable groups of the population for trachoma infection [14]. Two-fifth of active trachoma infection is occurred among children of age 1-9 years [3]. Active trachoma infection (trachomatous inflammation follicularis and/or trachomatous inflammation intense) reaches peak at the age of pre-school (4-6 years); however, subsequent scarring and blindness can also be occurred among children [7]. Blindness affect not only individuals but also several poverty reduction strategies [15]. Visual impairment can lead to annual productivity loss of $\$ 3-\$ 6$ billion in the world. Hence, sustainable development goal cannot be achieved in 2030 [16]. In Ethiopia, trachoma is the country's second most common cause of blindness next to cataract [17]. Approximately two-fifth of blindness is believed to be avoidable in Ethiopia prevention and early treatment [15]. Currently, despite of significant effort made to eliminate trachoma, trachoma is still a major health crisis in Ethiopia [18].

Multiple factors are assumed to be associated with active trachoma infection [13]. Specially, active trachoma infection among children is caused by presence of flies on the face [19], large family size [20], ocular discharge, nasal discharge, low socioeconomic status, living in higher altitude and unsafe water sources [21]. On the contrary, frequent washing of children's face, clean environment and hygienic disposal of excrement were found to be preventative factors [22]. Several studies indicate that open field defecation is the main risk factor for trachoma infection [19, 23, 24]. On the contrary, other evidence proved that latrine access was not associated with active trachoma or C. trachomatis infection, despite the fact that $60 \%$ of individuals do not have access to a latrine. Latrine access does not translate into latrine use [25].

World health organization has targeted trachoma to eliminate trachoma from being as a public health problem by 2020. Therefore, SAFE strategy (surgery for inturned eyelashes, antibiotics to clear infection, and facial cleanliness and environmental cleanness) was designed and implemented in the last couple of years in the world $[25,26]$. The targets for elimination of trachoma in Ethiopia include: Reduce prevalence of Trachomatous inflammation follicular below 5\% among children for children aged 1-9 years at the health district level and to minimize trachomatous trichiasis (TT) less than one case per 1000 among the total population at health district level [27]. As a result, policymakers and program designers should know the prevailing problem and 
factors hindering the elimination of trachoma to design better and logical programs and policy. In this study, we hypothesized that active trachoma should be significantly higher in open field defecation Kebeles than nonopen field defecation.

\section{Methods}

\section{Study design, setting and period}

This comparative cross-sectional study was conducted to determine the prevalence and factors associated with active trachoma infection among primary school children. This study was carried out in the technology village of Hawassa University, Southern Ethiopia. It is located in Sidama regional state $310 \mathrm{~km}$ from the capital city of the Ethiopia (Addis Ababa). Specifically, the village is found in Boricha and dale districts. It consists 6 districts and 168 Kebeles. An estimated 636, 146 (97\%) people live in rural areas. The total health service coverage of the village was $85 \%$. Generally, there are 633 primary schools in Sidama regional state. There were 360,547 (181,543males and 179,004 females) school age children in the region. The common cause of disease and disability in the region is associated with lack of clean drinking water, poor sanitation and low public awareness about environmental health and personal hygiene practices in the region. As of 2010/2011 population estimation report, Boricha and Dale districts had a total of 42 and 39 Kebeles respectively. There were 1 hospital, 17 health centres 74 health posts 7 private medium clinics and 1 non-governmental clinic in both districts. The study was done in primary schools (1-6 grades) of Kebeles; the technology Village of Hawassa University, in Boricha and Dale districts. This study was conducted from June 1-30; 2019.

\section{Sample size and sampling procedure}

The minimum sample size, which can meet the study's objectives, was determined by balancing of the following components of the study: Power, precision, baseline proportion, quality and cost of the study. The sample size was calculated for both prevalence of active trachoma infection and factors associated with active trachoma infection. Hence, the calculated sample size using variables from the study of blindness, low vision and trachoma in Ethiopia gave the largest sample size of 678 for this study [3]. Furthermore, assuming 10\% non-response rate, the final sample size was estimated as 746 for this study.

A total of 4 from 12 Kebeles were selected in the study settings. Two Kebeles were selected from each district (One from ODF and One from Non-ODF). They were selected purposefully considering the following assumptions: Absence of trachoma project in these Kebeles at the time of study period, their representativeness for latrine coverage and water coverage. Regarding about sample Kebeles, Debub Mesenkela (ODF) and Tula (Non-ODF) were selected from Dale district and Yirba Dewoncho (Non-ODF) and Konsore Arkie (ODF) were selected from Boricha district. Study participants were selected using simpe random sampling (lottery) scheme. Updated list (roster) of the students was utilized as the sampling frame in each section. The sample size for each section was allocated was using probability proportional to the total number of student for that section. Revisits of two times were made in case where eligible respondents were not available at the time of the data collection.

\section{Population}

In this study, the source population were all primary school children in both Boricha and Dale districts. Whereas, the study population were primary school students who were selected for this study and presented at time of data collection. Each child was the study unit in this study. School children who were actively learnt for more than 6 months in the selected primary schools were included in the study. Children who were unable to give response at the time of data collection due to severe illness like: Mental illness, unconsciousness and depression were excluded from this study.

\section{Study variables}

Outcome variable was the presence of active trachoma infection. Active trachoma infection is defined as Trachomatous inflammation-follicular or Trachomatous inflammation-intense or Trachomatous scarring among children age 1-9 years. The outcome variable is dichotomized. If active trachoma was proved to exist, it were labelled as " 1 "; otherwise, " 0 ". The independent variables were include the socio-demographic characteristics of the children's parent: Mother's educational status, father's educational status, ethnicity, family income, religion, and child care taking practice, family size, and parent's marital status and sharing room with animals. Moreover, behavioural characteristics of study subjects included: Ocular discharge, nasal discharge, flies on face, finger cleanness, open defecation field and status of cloth cleanness. The age of the study participants were taken from the sampling frame. Wealth index was calculated using principal components analysis [28]. It was formed in three stages containing many indicators [29].

\section{Data collection}

In this study, various types of data collection method were used. Data was collected through face to face interview, and ophthalmic examination. We have adopted questionnaire from national survey on blindness, low vision and trachoma in Ethiopia. Furthermore, we have 
adapted standard checklist from Thylefors, B simple system for assessment of trachoma and its complications $[6,11,30]$. The tool was first developed in English and translated into Sidama afoo (local language) and then back to English to keep its consistency. Comparison was done between two versions to assess inconsistent and inaccurate data. School principals arranged appropriate time and place for data collection. Data were collected by eight qualified and trained BSC degree ophthalmic professionals for ophtalaminc examination. Furthermore, there were four BSC nurses who collect socio-demographic and hygiene-related information. Two masters of public health (MPH) professions supervised data collection process of this study. They had previous experience in supervising data collection. Finally, any inconsistent and inaccurate data were corrected accordingly.

\section{Data analysis}

Analysis was done using SPSS version 24. Descriptive analysis was made using percentage, mean, standard deviations for variables included in the study. Bivariate and multivariate logistic regression analyses were done to identify the association between the independent and outcome variables. Before the actual logistic regression analysis was done, the necessary assumption of logistic regression model was checked. Frequencies were first determined followed by cross tabulations to compare frequencies. At bi-variate level, analysis was made by the chi square $\left(\mathrm{X}^{2}\right)$ test for categorical variables. The association between dependent and independent variables was measured by means of odds ratio for which $95 \%$ confidence interval was calculated. Variables which showed a statistically significant association $(p<0.25)$ at bivariate logistic regression analysis was further fitted into multivariate logistic regression analysis. Finally, variables which have $P$-value of less than 0.05 were considered as significantly associated factors of 'trachoma infection' in the multivariable logistic regression analysis. Adjusted odds ratios with the $95 \%$ Confidence Intervals $(\mathrm{CI})$ were reported. Hosmer-Lemeshow test of goodness of fit was used to check model fitness.

\section{Data quality control}

Data collectors and supervisors were given three-day training before the start of actual data collection time. The training was focused on the aim of the study, sampling procedure and data collection technique. Qualified and re-oriented ophthalmic professionals were recruited. Before utilization in the field, the data collection tool for ophtalaminc examination was calibrated accurately. All data were registered immediately after collection, and checked for completeness. Pre-test was conducted on $37(5 \%)$ of study participants in Wondogent district which is out of the current study settings.

\section{Ethics approval and consent to participate}

Ethical clearance was obtained from Institutional Review Board (IRB) of College of Medicine and Health Science of Hawassa University. Furthermore, regional and district health offices were communicated through official letter of permission. Relevant school directors and teachers were well informed about the scope and objective of the study. The study protocol was clarified for parents /legal guardians/ of the study subjects and informed written consent was taken from parents or legal guardians of the study participants. Children were treated with $1 \%$ TTC eye ointment or referred if they were infected with active trachoma.

\section{Results}

From a total number of 748 study participants, only 701(94\%) study participants gave full response in the this study. The socio-demographic characteristic of the study population is shown in Table 1 . Regarding the fathers of children in the study, only $14.2 \%$ from ODF and $8.5 \%$ from non-ODF Kebeles of could read and write. Nearly one third (31.6\%) of children lived in the middle wealth quintile household. Three hundred seventy three (53.2\%) of parents of the study subjects cared for their children.

Accordingly, one out of two study participants were selected from open field defecation Kebeles and the remaining study subjects were selected from non-open field defecation Kebeles. Based on the districts, more than half $(55.9 \%)$ of study participants were selected from Boricha district; whereas, the remaining 45.1\% were selected from Dale district. More than four-fifth of the study participants had ocular discharge at the time of data collection. Nighty eight (14.4\%) of the study participants had nasal discharge at the time of data collection. More than half $(54.4 \%)$ of the study participants had no finger cleanness during inspection at data collection. Males accounted more than half (51.4\%) of study subjects in the current study. Most of the study participants were in the age range of 5-9 years $(82.7 \%)$, the mean age of $8.8 \pm 1.67$ years. Regarding about cloth hygiene, more than half (53.5\%) of the study participants had no cloth cleanness. Only 1 out of $10(8.3 \%)$ study participants had fly on their face, while most $(91.7 \%)$ of children did not have fly on their face during data collection time. According to Table 2 report, we found that the overall prevalence of active trachoma infection was $17.5 \%$ among primary school students in the study area. Specifically, the prevalence of trachoma infection was $67.5 \%$ in the ODF villages, while the prevalence of active trachoma infection was $32.5 \%$ in non-ODF Kebeles.

\section{Factors associated with active trachoma infection}

According to Table 3 reports, living in ODF Kebeles, being female, having ocular discharge, having nasal 
Table 1 Socio-demographic characteristics of the children's parent in Dale and Boricha districts, Sidama Ethiopia, in 2019( $n=701)$

\begin{tabular}{|c|c|c|c|c|}
\hline Characteristics & Category & ODF & Non- ODF & Total \\
\hline \multirow[t]{5}{*}{ Mothers educational status } & Can nor read and write & $145(20.7 \%)$ & $145(20.7 \%)$ & $290(41.37)$ \\
\hline & Read and write & $118(16.8 \%)$ & $40(5.7 \%)$ & $158(22.54)$ \\
\hline & Primary & $135(19.3 \%)$ & $5(0.7 \%)$ & $140(19.97)$ \\
\hline & Secondary & $26(3.7 \%)$ & $7(1 \%)$ & $33(4.71)$ \\
\hline & College and above & $76(10.8 \%)$ & $4(0.6 \%)$ & $80(11.41)$ \\
\hline \multirow[t]{5}{*}{ Fathers educational status } & Cannot read and write & $299(42.7 \%)$ & $561(80 \%)$ & $160(22.82)$ \\
\hline & Read and write & $122(17.4 \%)$ & $81(11.6 \%)$ & $203(28.96)$ \\
\hline & Primary education & 99 (14.1\%) & $3(0.4 \%)$ & $102(14.55)$ \\
\hline & Secondary education & $69(9.9 \%)$ & $14(2 \%)$ & $83(11.84)$ \\
\hline & College and above & $111(15.9 \%)$ & $42(6 \%)$ & $153(21.83)$ \\
\hline \multirow[t]{4}{*}{ Religion } & Protestant & $94(13,4 \%)$ & $17(2.4 \%)$ & $111(15.83)$ \\
\hline & Orthodox & $51(7.2 \%)$ & $196(28 \%)$ & $247(35.24)$ \\
\hline & Muslim & $42(6 \%)$ & $252(36 \%)$ & $294(41.94)$ \\
\hline & Others & $7(1 \%)$ & $42(6 \%)$ & $49(6.99)$ \\
\hline \multirow[t]{4}{*}{ Ethnicity } & Oromo & $56(8) \%$ & $42(6 \%)$ & $98(13.98)$ \\
\hline & Amhara & $26(18 \%)$ & $84(12 \%)$ & $110(15.69)$ \\
\hline & Sidama & $144(20.5 \%)$ & $220(31.3 \%)$ & $364(51.93)$ \\
\hline & Others & $70(10 \%)$ & $59(8.4 \%)$ & $129(18.40)$ \\
\hline \multirow[t]{5}{*}{ Economic status } & Poorest & 75 (10.6\%) & $96(13.6 \%)$ & $171(24.39)$ \\
\hline & Poor & $47(7 \%)$ & $68(9.7 \%)$ & $116(16.55)$ \\
\hline & Middle & $168(24 \%)$ & $54(7 . \%)$ & $222(31.67)$ \\
\hline & Rich & $25(3.6 \%)$ & $84(12 \%)$ & 109 (15.55) \\
\hline & Richest & $56(8 \%)$ & $28(3.9 \%)$ & $84(11.98)$ \\
\hline \multirow[t]{2}{*}{ Child care taking } & Care taker & $289(41.2 \%)$ & $84(12 \%)$ & $373(53.21)$ \\
\hline & Non-care taker & $266(38 \%)$ & $62(8.8 \%)$ & $328(46.7) 9$ \\
\hline \multirow[t]{2}{*}{ Family size } & $<4$ persons & $369(52.6 \%)$ & $40(5.7 \%)$ & 409 (58.35) \\
\hline & $>4$ persons & $232(33 \%)$ & $60(8.5 \%)$ & $292(41.65)$ \\
\hline \multirow[t]{4}{*}{ Marital status } & Married & $148(21.1 \%)$ & $322(46 \%)$ & $470(67.05)$ \\
\hline & Divorced & $84(12 \%)$ & 77 (10.9\%) & $161(22.97)$ \\
\hline & Widowed & $14(2 \%)$ & $42(6 \%)$ & $56(7.99)$ \\
\hline & Single & $14(2 \%)$ & $49(7 \%)$ & $63(8.99)$ \\
\hline \multirow[t]{2}{*}{ Sharing room with animals } & Yes & $290(41.3 \%)$ & $299(42.7 \%)$ & $589(84.02)$ \\
\hline & No & 65 (9.3\%) & 47 (6.7\%) & $112(15.98)$ \\
\hline
\end{tabular}

discharge and having flies on the face, cloth cleanness and finger cleanness were factors associated with active trachoma infection in chi-square statistics $\left(\mathrm{X}^{2}\right)$ ). Moreover, all variables which show significant association in chi-square distribution statistics were further analysed in the binary logistic regression analysis. Hence, living in ODF Kebeles, being female, having ocular discharge, having nasal discharge and having flies on the face were factors positively associated with active trachoma. On the contrary, cloth cleanness and finger cleanness were factors negatively associated with active trachoma in the current study.
Based on the report of Table 4, except cloth cleanness, factors which significant association in bivariate logistic regression analysis model also significantly associated in the multivariate logistic regression analysis model. On the other hand, family size, child caring practice, sharing of rooms with animals, educational status and wealth quintile did not show significantly association in this study. Primary school children in the ODF schools were 2.5 times more likely to be infected with active trachoma infection than their counterparts $(\mathrm{AOR}=2.52,95 \% \mathrm{CI}$, $1.5-4.1, p<0.000)$. The odd of getting active trachoma among female primary school children were 1.63 times 
Table 2 Behavioral characteristics of study participants in Boricha and Dale districts, Sidama Ethiopia, in 2019 ( $n=701)$

\begin{tabular}{|c|c|c|}
\hline Variables & Number of students & Percent \\
\hline \multicolumn{3}{|l|}{ Kebeles } \\
\hline Debub Mesenkela & 152 & 21.7 \\
\hline Tula & 157 & 22.4 \\
\hline KA & 201 & 28.7 \\
\hline Yirba dewoncho & 191 & 27.2 \\
\hline \multicolumn{3}{|l|}{ Woreda } \\
\hline Boricha & 392 & 55.9 \\
\hline Dale & 309 & 44.1 \\
\hline \multicolumn{3}{|l|}{ Age } \\
\hline $5-9$ years & 580 & 82.7 \\
\hline 10-14 years & 131 & 18.7 \\
\hline 15 years and above & 90 & 12.8 \\
\hline \multicolumn{3}{|l|}{ Sex } \\
\hline Male & 360 & 51.4 \\
\hline Female & 341 & 48.6 \\
\hline \multicolumn{3}{|l|}{ Ocular discharge } \\
\hline Yes & 135 & 19.3 \\
\hline No & 566 & 80.7 \\
\hline \multicolumn{3}{|l|}{ Nasal discharge } \\
\hline Yes & 101 & 14.4 \\
\hline No & 600 & 85.6 \\
\hline \multicolumn{3}{|l|}{ Fly on face } \\
\hline Yes & 58 & 8.3 \\
\hline No & 643 & 91.7 \\
\hline \multicolumn{3}{|l|}{ Finger cleanliness } \\
\hline Yes & 320 & 45.6 \\
\hline No & 381 & 54.4 \\
\hline \multicolumn{3}{|l|}{ Cloth cleanliness } \\
\hline Yes & 326 & 46.5 \\
\hline No & 375 & 53.5 \\
\hline \multicolumn{3}{|l|}{ Trachoma infection } \\
\hline Yes & 123 & 17.5 \\
\hline No & 578 & 82.5 \\
\hline \multicolumn{3}{|l|}{ Type of trachoma } \\
\hline TF & 71 & 57.7 \\
\hline $\mathrm{Tl}$ & 37 & 30.1 \\
\hline TS & 15 & 12.2 \\
\hline \multicolumn{3}{|l|}{ ODF status } \\
\hline ODF & 353 & 50.4 \\
\hline Non-ODF & 348 & 49.6 \\
\hline
\end{tabular}

Key: TF Trachomatous inflammation Foliculris, $T$ T Trachomatous Inflammation Intense, Trachomatous Scarring, ODF Open defecation field
Table 3 Hygiene and sanitation status of the study subjects in Boricha and Dale districts, Sidama Ethiopia, $2019(n=701)$

\begin{tabular}{|c|c|c|c|}
\hline \multirow[t]{2}{*}{ Variables } & \multicolumn{3}{|l|}{ ODF Status } \\
\hline & ODF N(\%) & Non ODF N(\%) & $\mathrm{X}^{2} ; p$ value \\
\hline \multicolumn{4}{|c|}{ Trachoma infection } \\
\hline Yes & $83(67.5 \%)$ & 40 (32.5\%) & $17.496,0.000$ \\
\hline No & $270(46.7 \%)$ & $308(53.3 \%)$ & \\
\hline \multicolumn{4}{|c|}{ Ocular discharge } \\
\hline Yes & $72(53.3 \%)$ & $63(46.7 \%)$ & $0.593 ; 0.441$ \\
\hline No & $281(49.6 \%)$ & 285 (50.4\%) & \\
\hline \multicolumn{4}{|c|}{ Nasal discharge } \\
\hline Yes & $52(51.5 \%)$ & $49(48.5 \%)$ & $0.06 ; 0.8$ \\
\hline No & $301(50.2 \%)$ & 299 (49.8\%) & \\
\hline \multicolumn{4}{|c|}{ Fly on face } \\
\hline Yes & $32(55.2 \%)$ & $26(44.8 \%)$ & $0.587 ; 0.444$ \\
\hline No & $321(49.9 \%)$ & $322(50.1 \%)$ & \\
\hline \multicolumn{4}{|c|}{ Finger cleanliness } \\
\hline Yes & $150(46.9 \%)$ & $170(53.1 \%)$ & $2.855 ; .091$ \\
\hline No & $203(53.3 \%)$ & $178(46.7 \%)$ & \\
\hline \multicolumn{4}{|c|}{ cloth cleanliness } \\
\hline Yes & $155(47.5 \%)$ & $171(52.5 \%)$ & $1.926 ; 0.165$ \\
\hline No & $198(52.8 \%)$ & $177(47.2 \%)$ & \\
\hline
\end{tabular}

higher than males $(\mathrm{AOR}=1.6 ; 95 \% \mathrm{CI}, 1.2-2.6, p<$ 0.046). The chance of children who had ocular discharge was 5.7 times more than their counterparts $(\mathrm{AOR}=5.71$, 95\% CI, 3.5-9.4, $p<0.000$ ). The likelihood of children with nasal discharge were 1.8 times more likely than their counterparts $(\mathrm{AOR}=1.89,95 \% \mathrm{CI}, 1.06-3.39, p<$ 0.031 ). The odd of children with flies on their face were 6.5 times more likely than their counterparts (AOR = 6.5, 95\% CI, 3.3, 12.4, $p<0.000$ ). Furthermore, those children with clean finger were experienced $57 \%$ points less likely to be infected with active trachoma infection than their counterparts $(\mathrm{AOR}=0.43,95 \% \mathrm{CI}, 0.21,0.86$, $p<0.018$ ).

\section{Discussion}

We anticipated high prevalence of active trachoma in open field defecation Kebeles among children of 1-9 years in this study. However, it has demonstrated that active trachoma was found to be high in non-open field defecation Kebeles. The prevalence of active trachoma among school children was $76.5 \%$ in ODF Kebeles; the prevalence of active trachoma was $88.5 \%$ among school children who live in Non-ODF Kebeles. This proportion was statistically significant $\left(x^{2}=17.5, p\right.$-value $\left.<0.000\right)$. These findings indicate that $12 \%$ of excess active trachoma was observed among school children in non-ODF Kebeles. This mainly indicates that presence of latrine 
Table 4 Factors associated with active trachoma infection from backward stepwise (Wald) logistic regression analysis among study participants in Boricha and Dale districts, Sidama Ethiopia, in $2019(n=701)$

\begin{tabular}{|c|c|c|c|c|}
\hline \multirow{2}{*}{$\begin{array}{l}\text { Hygiene } \\
\text { conditions }\end{array}$} & \multicolumn{3}{|c|}{ Trachoma infection } & \multirow[b]{2}{*}{$P$-value } \\
\hline & $\begin{array}{l}\text { Yes } \\
\text { N (\%) }\end{array}$ & $\begin{array}{l}\text { No } \\
\mathrm{N}(\%)\end{array}$ & AOR $(95 \% \mathrm{Cl})$ & \\
\hline \multicolumn{5}{|l|}{ ODF status } \\
\hline ODF & $270(76.5 \%)$ & $83(23.5 \%)$ & $2.52(1.5-4.1)$ & 0.000 \\
\hline Non-ODF & 308 (88.5\%) & $40(11.5 \%)$ & 1 & \\
\hline \multicolumn{5}{|c|}{ Sex of students } \\
\hline Male & 305 (84.7\%) & $55(15.3 \%)$ & 1 & \\
\hline Female & $273(80.1 \%)$ & $68(19.9 \%)$ & 1.631 (1.009-2.638) & 0.046 \\
\hline \multicolumn{5}{|c|}{ Ocular discharge } \\
\hline Yes & $66(48.9 \%)$ & $69(51.1 \%)$ & 5.715 (3.468-9.418) & 0.000 \\
\hline No & $57(10.1 \%)$ & $509(89.9 \%)$ & 1 & \\
\hline \multicolumn{5}{|c|}{ Nasal discharge } \\
\hline Yes & $42(41.6 \%)$ & $59(58.4 \%)$ & $1.898(1.060-3.399)$ & 0.031 \\
\hline No & $81(13.5 \%)$ & $519(86.5 \%)$ & 1 & \\
\hline \multicolumn{5}{|l|}{ Fly on face } \\
\hline Yes & $35(60.3 \%)$ & $23(39.7 \%)$ & $6.472(3.366-12.444)$ & 0.000 \\
\hline No & $88(13.7 \%)$ & $555(86.3 \%)$ & 1 & \\
\hline \multicolumn{5}{|c|}{ Finger cleanliness } \\
\hline Yes & $27(8.4 \%)$ & $293(91.6 \%)$ & $.431(.215-.863)$ & 0.018 \\
\hline No & $96(25.2 \%)$ & $285(74.8 \%)$ & 1 & \\
\hline \multicolumn{5}{|c|}{ Cloth cleanliness } \\
\hline Yes & $28(8.6 \%)$ & $298(91.4 \%)$ & $.647(.326-1.285)$ & 0.214 \\
\hline No & 95 (25.3\%) & $280(74.7 \%)$ & 1 & \\
\hline
\end{tabular}

only does not give guarantee for prevention of active trachoma elimination rather the health behaviour related with hygiene determine the prevalence of active trachoma. From this, we can understand effective utilization of latrine, hand hygiene after utilization of latrine and increase awareness about active trachoma are mandatory apart from transforming ODF Kebeles to non ODF status. The overall prevalence of active trachoma infection was $17.5 \%$ (95\% CI, 16.1-18.8) among primary school students aged 1-9 years. Specifically, prevalence of trachoma infection was 55.9 and $44.1 \%$ in Boricha and Dale district respectively. These findings are reduced almost by half when compared with prevalence of active trachoma in Southern Nation Nationalities Regional State (33.2\%). Furthermore, these findings were also lower than age adjusted prevalence of South region (25.9\%) [3]. The possible rational for this difference might be due to lack of awareness about personal hygiene and sanitation. Besides, lack of water and hygiene materials in this study might result into higher trachoma infection. Compared to prevalence of active trachoma in 2014, prevalence of active trachoma was higher in 2019 in the study area [31]. This might indicate that despite progress in prevention of active trachoma in the region, little effort was made to prevent active trachoma in the study area in the last couple of years. Ethiopian federal ministry of health, and other stakeholders have identified various type of strategy to control and eradicate active trachoma like: Hygiene and promotion, improved access to clean water, and proper sanitation for disposal of human waste as a priority intervention for trachoma infection and other wash related disease through the health extension program and adoption of community-led total Sanitation [32]. The current study showed that prevalence of active trachoma inflammation follicular (TF) was found to be $55.7 \%$. The current finding is more than the WHO criteria for elimination of trachoma as public health problem i.e. $\mathrm{TF}<5 \%$ in children aged from 1 to 9 years (WHO) [33]. This might be due to absence of universal supplementation of antibiotics, facial cleanliness and environmental cleanness strategy for trachoma elimination. Previous evidence recommend A, F and E components of the SAFE (Surgery, Antibiotic, Facial cleanliness and Environmental improvement) strategy for trachoma elimination for settings with prevalence of active trachoma infection more than 5\% [34]. Primary 
school children in ODF Kebeles were two and half times more likely prone for active trachoma infection than their counterparts. This finding is in line with previous study conducted in Southern parts of Ethiopia [31, 35]. The possible explanation could be the following: Firstly, active trachoma infection might be due lack of personal hygiene (finger cleanness, facial cleanness and environment hygiene) more than latrine utilization. This indicates that the mere presence of latrine could not guarantee the prevention of active trachoma infection unless appropriate hygiene practices are not performed after latrine utilization [36]. Secondly, community led total sanitation campaigns are practiced by ODF Kebeles more than non-ODF Kebeles. Finally, health education program might be strengthened by community health workers about personal hygiene, environmental sanitation and disease prevention in ODF Kebeles than their counterparts. Similar studies also approved this fact that health education intervention statistically significant reduction in the prevalence of active trachoma [22]. Finally, in these populations children aged 1-9 years are often discouraged from using latrines due to caregiver concerns about their safety when using latrines.

The odd of getting active trachoma infection among primary school children who had flies on their face is higher than their counterparts. This finding is consistent with finding of similar study carried out in East Nigeria [19, 37-39]. The possible rational might be that school children with flies on their face did not wash their face frequently due to lack of water source. Previous evidence indicate that improving access to safe water sources and better hygiene practices can reduce trachoma morbidity nearly by one third [40]. As previous evidence proved that frequent washing of children, clean environment and hygienic disposal of excretion were valuable preventative factors for active trachoma infection [22].

In this study, females were more affected by active trachoma infection than males. This finding is inconsistent with the previous study done in Guinea [41]. On the contrary, females have low odds of getting trachoma infection in the study conducted in Biogas [42]. The possible explanation might be female children are in close contact with vectors and other exposure variables during home works. In addition, some communities might have sex preference in taking care of children.

The chance of children who had ocular discharge more than their counterparts. This finding is consistent with the previous study. This finding is in line with the previous study [41]. The possible rational might be that children who had ocular discharge were more likely to attract flies on their eye and less likely to wash with clean water and soap. Similar study proved that children who did not wash their face with soap and water were more likely affected by active trachoma infection [43].
Children with nasal discharge were more affected than their counterparts. This finding is similar with the previous study [41]. This might be due to the fact that nasal discharge might create good media for attracting flies on their face causing active trachoma infection. Flies are vectors of chlamydia trichromatic infection [44]. Nasal and ocular discharges might result from the inflammation of active trachoma and cause the face to be classified as unclean $[24,45,46]$. At last, children with clean finger had lower risk of infection than their counterparts [47]. The possible explanation might be due to the fact that children with unclean finger had chlamydia Trachomatous with their finger and subsequent transmission through direct contact at the time of touching of their eyes.

\section{Limitation of the study}

This study had number strengths. First, it yields the most reliable result that was conducted with appropriate design and adequate sample size. Second, the response rate was good which further strength the generalization. Finally, we have used random sampling and appropriate mixed type of data collection to incur data at a maximum effort. On the contrary, this study could address only primary school children as it limits the extent of generalization. The cross sectional nature of the study did not show the cause and effect relationship. Furthermore, as the study was a school based one, other risk factors which might be apparent at household and neighbourhood level were not assessed. Hence, multilevel and follow up studies should be conducted to fill this gap.

\section{Conclusion}

Prevalence of active trachoma is high among school children in open field defecation than school children of non-open field defecation. Furthermore, the prevalence of active trachoma among school children is higher than the national prevalence in both areas. Hence, the government should strength proper environmental sanitation, hand hygiene and proper use of latrine. Campaigns focusing on introducing educational intervention programs in women's organizations, schools, and communities could help bring behavioural changes among school children, which are the change agents, and lower the burden of trachoma in the study area.

\section{Abbreviations}

AOR: Adjusted odds ratio; Cl: Confidence interval; OR: Odds ratio; ODF: Open defecation free; HEW: Health extension worker; CLTS: Community led total sanitation; NGO: Non-governmental organization; WHO: World health organization; SNNP: Southern nation nationality and peoples

\section{Acknowledgements}

The authors would like to thank our data collectors and supervisor for theirinvaluable effort. Our deepest gratitude also goes to study participants 
fortheir voluntary participation. We are also grateful for workers of Dale and Boricha districts health offices. Finally, we want to thank Hawassa University College of Medicine and Health Sciences for giving this chance.

\section{Authors' contributions}

$\mathrm{DD}, \mathrm{HB}$ wrote the proposal, designed the methodology analysed the data and drafted the first draft of manuscript. AT, and BT designed methodology, data analysis and interpretation of the result, and drafted the initial manuscript. All the authors revised, read and approved the subsequent drafts of the manuscript.

\section{Funding}

No funding.

\section{Availability of data and materials}

We have sent all the available data and we do not want to share the raw data as we are doing related study.

\section{Declarations}

\section{Ethics approval and consent to participate}

Ethical clearance was obtained from Institutional Review Board (IRB) of College of Medicine and Health Science of Hawassa University. Furthermore, regional and district health offices were communicated through official letter of permission. Relevant school directors and teachers were well informed about the scope and objective of the study. The study protocol was clarified for parents /legal guardians/ of the study subjects and informed written consent was taken from parents or legal guardians of the study participants. Children were treated with $1 \%$ TTC eye ointment or referred if they were infected with active trachoma.

\section{Consent for publication}

Not applicable.

\section{Competing interests}

All the authors declare that they have no competing interests.

\section{Author details}

${ }^{1}$ Department of Ophthalmology, College of Medicine and Health Science, Hawassa University, Hawassa, Ethiopia. ${ }^{2}$ Department of Enviromental Health Science, College of Medicine and Health Science, Hawassa University, Hawassa, Ethiopia. ${ }^{3}$ Department of Environmental Health, College of Medicine and Health Science, Hawassa University, Hawassa, Ethiopia. ${ }^{4}$ Department of Midwifery, College of Medicine and Health Science, Hawassa University, Hawassa, Ethiopia.

Received: 7 December 2020 Accepted: 26 October 2021

Published online: 09 November 2021

\section{References}

1. Mabey D, et al. Antibiotics for trachoma. Cochrane Database Syst Rev. 2002; 1. https://doi.org/10.1002/14651858.CD001860.

2. Emerson $P$, et al. Human and other faeces as breeding media of the trachoma vector Musca sorbens. Med Vet Entomol. 2001;15(3):314-20. https://doi.org/10.1046/j.0269-283x.2001.00318.x.

3. Berhane Y, Worku A, Bejiga A, Adamu L, Alemayehu W, Bedri A, et al. Prevalence of trachoma in Ethiopia. Ethiop J Health Dev (EJHD). 2007;21(3). https://doi.org/10.4314/ejhd.v21i3.10051.

4. Smith JL, Flueckiger RM, Hooper PJ, Polack S, Cromwell EA, Palmer SL, et al. The geographical distribution and burden of trachoma in Africa. PLoS Negl Trop Dis. 2013;7(8):e2359. https://doi.org/10.1371/journal.pntd.0002359.

5. Burton MJ, Mabey DC. The global burden of trachoma: a review. PLoS Negl Trop Dis. 2009;3(10):e460. https://doi.org/10.1371/journal.pntd.0000460.

6. Thylefors B, Dawson CR, Jones BR, West SK, Taylor HR. A simple system for the assessment of trachoma and its complications. Bull World Health Organ. 1987;65(4):477-83.

7. Solomon AW, Peeling RW, Foster A, Mabey DCW. Diagnosis and assessment of trachoma. Clin Microbiol Rev. 2004;17(4):982-1011. https://doi.org/10.112 8/CMR.17.4.982-1011.2004.

8. Resnikoff S, Pascolini D, Etya'ale D, Kocur I, Pararajasegaram R, Pokharel GP, et al. Global data on visual impairment in the year 2002. Bull World Health
Organ. 2004;82(11):844-51. https://doi.org/10.1590//S0042-968620040011 00009.

9. Mpyet C, Lass BD, Yahaya HB, Solomon AW. Prevalence of and risk factors for trachoma in Kano state. Nigeria PLoS One. 2012;7(7):e40421. https://doi. org/10.1371/journal.pone.0040421.

10. Alene $\mathrm{G}$, Abebe $\mathrm{S}$. Prevalence of risk factors for trachoma in a rural locality of Northwestern Ethiopia. East Afr Med J. 2000;77(6). https://doi.org/10.4314/ eamj.v77i6.46638.

11. Berhane $Y$, et al. National survey on blindness, low vision and trachoma in Ethiopia: methods and study clusters profile. Ethiop J Health Dev. 2007; 21(3):185-203.

12. Berhane $Y$, et al. Prevalence and causes of blindness and low vision in Ethiopia. Ethiop J Health Dev. 2007;21(3):204-10.

13. Cumberland P, Edwards T, Hailu G, Harding-Esch E, Andreasen A, Mabey D, et al. The impact of community level treatment and preventative interventions on trachoma prevalence in rural Ethiopia. Int J Epidemiol. 2008;37(3):549-58. https://doi.org/10.1093/ije/dyn045.

14. Alemayehu W, Melese M, Fredlander E, Worku A, Courtright P. Active trachoma in children in Central Ethiopia: association with altitude. Trans $\mathrm{R}$ Soc Trop Med Hyg. 2005;99(11):840-3. https://doi.org/10.1016/j.trstmh.2005. 06.013 .

15. Budden F. A report on blindness in Ethiopia. Geneva: WHO, STC; 1981.

16. Wright HR, Turner A, Taylor HR. Trachoma. Lancet. 2008;371(9628):1945-54. https://doi.org/10.1016/S0140-6736(08)60836-3.

17. Bourne RR, Stevens GA, White RA, Smith JL, Flaxman SR, Price $H$, et al. Causes of vision loss worldwide, 1990-2010: a systematic analysis. Lancet Glob Health. 2013;1(6):e339-49. https://doi.org/10.1016/\$2214-109X(13 )70113-X.

18. Gebrie A, Alebel A, Zegeye A, Tesfaye B, Wagnew F. Prevalence and associated factors of active trachoma among children in Ethiopia: a systematic review and meta-analysis. BMC Infect Dis. 2019;19(1):1073. https://doi.org/10.1186/s12879-019-4686-8.

19. Mpyet C, Goyol M, Ogoshi C. Personal and environmental risk factors for active trachoma in children in Yobe state, North-Eastern Nigeria. Tropical Med Int Health. 2010;15(2):168-72. https://doi.org/10.1111/j.1365-3156.2009. 02436.x.

20. Regassa K, Teshome T. Trachoma among adults in Damot Gale District, South Ethiopia. Ophthalmic Epidemiol. 2004;11(1):9-16. https://doi.org/10.1 076/opep.11.1.9.26440.

21. Ngondi J, Gebre T, Shargie EB, Adamu L, Ejigsemahu Y, Teferi T, et al. Evaluation of three years of the SAFE strategy (surgery, antibiotics, facial cleanliness and environmental improvement) for trachoma control in five districts of Ethiopia hyperendemic for trachoma. Trans R Soc Trop Med Hyg. 2009;103(10):1001-10. https://doi.org/10.1016/j.trstmh.2008.11.023.

22. Cumberland $\mathrm{P}$, Hailu G, Todd J. Active trachoma in children aged three to nine years in rural communities in Ethiopia: prevalence, indicators and risk factors. Trans R Soc Trop Med Hyg. 2005;99(2):120-7. https://doi.org/10.101 6/j.trstmh.2004.03.011.

23. Admassu F, et al. Active trachoma two years after three rounds of azithromycin mass treatment in Cheha district Gurage zone, southern Ethiopia. BMC Pediatr. 2013;13(1):1-5.

24. Baggaley $\mathrm{R}$, et al. Distance to water source and altitude in relation to active trachoma in Rombo district. Tanzania Trop Med Int Health. 2006;11(2):220-7. https://doi.org/10.1111/j.1365-3156.2005.01553.x.

25. O'Loughlin R, Fentie G, Flannery B, Emerson PM. Follow-up of a low cost latrine promotion programme in one district of Amhara, Ethiopia: characteristics of early adopters and non-adopters. Tropical Med Int Health. 2006;11(9):1406-15. https://doi.org/10.1111/j.1365-3156.2006.01689.x.

26. Bailey R, Lietman T. The SAFE strategy for the elimination of trachoma by 2020: will it work? Bull World Health Organ. 2001;79(3):233-6.

27. Organization, W.H. Validation of elimination of trachoma as a public health problem. Geneva: World Health Organization; 2016.

28. Rutstein SO. The DHS wealth index: approaches for rural and urban areas. Calverton: ICF International Measure DHS; 2008.

29. CSA-Ethiopia, I. International: Ethiopia demographic and health survey 2011. Ethiopia and Calverton, Maryland, USA: Central Statistical Agency of Ethiopia and ICF International Addis Ababa; 2012.

30. Organization, W.H., Malaria indicator survey: basic documentation for survey design and implementation. Geneva: World Health Organization UNICEF MEASURE DHS; MEASURE Evaluation U.S. Centers for Disease Control and Prevention; 2005. 
31. Adera TH, et al. Prevalence of and risk factors for trachoma in Southern Nations, Nationalities, and Peoples' Region, Ethiopia: results of 40 population-based prevalence surveys carried out with the Global Trachoma Mapping Project. Ophthalmic Epidemiol. 2016;23(sup1):84-93.

32. Hailu T. Ethiopia Trachoma Control Program-National Perspective: in "Achieving Elimination Targets". In: The Twelfth Annual Trachoma Control Program Review. Atlanta, Georgia: The Carter Center; 2011.

33. Mondiale de la santé O, W.H. Organization. Weekly Epidemiological Record. Relevé épidémiologique hebdomadaire. 2017;92(46):701-16.

34. Organization, W.H. WHO Alliance for the global elimination of trachoma by 2020: progress report on elimination of trachoma, 2014-2016. Wkly Epidemiol Rec. 2017;92(26):359-68.

35. Macleod CK, Binnawi KH, Elshafie BE, Sadig HE, Hassan A, Cocks N, et al. Unimproved water sources and open defecation are associated with active trachoma in children in internally displaced persons camps in the Darfur states of Sudan. Trans R Soc Trop Med Hyg. 2019;113(10):599-609. https:// doi.org/10.1093/trstmh/trz042.

36. WoldeKidan E, Daka D, Legesse D, Laelago T, Betebo B. Prevalence of active trachoma and associated factors among children aged 1 to 9 years in rural communities of Lemo district, southern Ethiopia: community based cross sectional study. BMC Infect Dis. 2019;19(1):886. https://doi.org/10.1186/s12 879-019-4495-0.

37. Emerson PM, Lindsay SW, Alexander N, Bah M, Dibba SM, Faal HB, et al. Role of flies and provision of latrines in trachoma control: cluster-randomised controlled trial. Lancet. 2004;363(9415):1093-8. https://doi.org/10.1016/S014 0-6736(04)15891-1.

38. Hägi M, Schémann JF, Mauny F, Momo G, Sacko D, Traoré L, et al. Active trachoma among children in Mali: clustering and environmental risk factors. PLoS Negl Trop Dis. 2010;4(1):e583. https://doi.org/10.1371/journal.pntd. 0000583.

39. Brechner RJ, West S, Lynch M. Trachoma and flies: individual vs environmental risk factors. Arch Ophthalmol. 1992;110(5):687-9. https://doi. org/10.1001/archopht.1992.01080170109035.

40. Water, S. and W.H. Organization, Water, sanitation and hygiene links to health: facts and figures. 2004.

41. Last AR, Burr SE, Weiss HA, Harding-Esch EM, Cassama E, Nabicassa M, et al. Risk factors for active trachoma and ocular chlamydia trachomatis infection in treatment-naive trachoma-hyperendemic communities of the Bijagós archipelago. Guinea Bissau PLoS Negl Trop Dis. 2014;8(6):e2900. https://doi. org/10.1371/journal.pntd.0002900.

42. Harding-Esch E, et al. Risk factors for active trachoma in the Gambia. Trans R Soc Trop Med Hyg. 2008;102(12):1255-62. https://doi.org/10.1016/j.trstmh.2 008.04.022.

43. Gedefaw M, Shiferaw A, Alamrew Z, Feleke A, Fentie T, Atnafu K. Current state of active trachoma among elementary school students in the context of ambitious national growth plan: the case of Ethiopia. Health. 2013; 2013(11):1768-73. https://doi.org/10.4236/health.2013.511238.

44. Farrar J, et al. Manson's Tropical Diseases E-Book. Heidelberg: Elsevier Health Sciences; 2013.

45. Stocks ME, Ogden S, Haddad D, Addiss DG, McGuire C, Freeman MC. Effect of water, sanitation, and hygiene on the prevention of trachoma: a systematic review and meta-analysis. PLoS Med. 2014;11(2):e1001605. https://doi.org/10.1371/journal.pmed.1001605.

46. Hsieh Y-H, et al. Risk factors for trachoma: 6-year follow-up of children aged 1 and 2 years. Am J Epidemiol. 2000;152(3):204-11.

47. Woldekidan $\mathrm{E}$, et al. Prevalence of active trachoma and associated factors among children aged 1 to 9 years in rural communities of Lemo district, southern Ethiopia: community based cross sectional study. BMC Infect Dis. 2019;19(1):1-8

\section{Publisher's Note}

Springer Nature remains neutral with regard to jurisdictional claims in published maps and institutional affiliations.

Ready to submit your research? Choose BMC and benefit from:

- fast, convenient online submission

- thorough peer review by experienced researchers in your field

- rapid publication on acceptance

- support for research data, including large and complex data types

- gold Open Access which fosters wider collaboration and increased citations

- maximum visibility for your research: over $100 \mathrm{M}$ website views per year

At BMC, research is always in progress.

Learn more biomedcentral.com/submissions 